\title{
DECOMPOSIÇÃO DE PALHA DE AVEIA PRETA E DEJETOS DE SUÍNOS EM SOLO SOB PLANTIO DIRETO ${ }^{(1)}$
}

\author{
Celso Aita ${ }^{(2)}$, Ivan Carlos Chiapinotto ${ }^{(3)}$, Sandro José Giacomini ${ }^{(2)}$, \\ André Paulo Hübner ${ }^{(4)}$ \& Marcelo Gonçalves Marques ${ }^{(5)}$
}

\begin{abstract}
RESUMO
A aplicação dos dejetos de suínos em sistema plantio direto é uma prática relativamente recente no Sul do Brasil. É necessário avaliar, nesse sistema, a decomposição dos dejetos, bem como seus efeitos sobre a decomposição dos resíduos culturais das plantas de cobertura. O objetivo deste trabalho foi avaliar a decomposição de dejetos de suínos e sua influência sobre a velocidade de decomposição da palha de aveia preta, em solo sob plantio direto. Para isso, foram realizados dois experimentos em condições de campo na UFSM, em um Argissolo Vermelho distrófico arênico. Imediatamente após aplicar as doses de 0 e $40 \mathrm{~m}^{3} \mathrm{ha}^{-1}$ de dejetos no interior de câmaras estáticas, em solo descoberto e em solo com palha de aveia na superfície, iniciou-se a medida da liberação de C$\mathrm{CO}_{2}$, a qual foi monitorada, durante 62 dias, no experimento 1, e durante 97 dias, no experimento 2. A cinética de decomposição diferiu entre os dejetos de suínos e a palha de aveia. Nos dejetos de suínos, houve uma fase inicial de rápida liberação de $\mathrm{C}_{-} \mathrm{CO}_{2}$, seguida de outra mais lenta, enquanto, na palha de aveia, a liberação de $\mathrm{C}_{-} \mathrm{CO}_{2}$ foi mais constante. Aproximadamente, um terço do $\mathrm{C}$ adicionado com os dejetos de suínos e com palha de aveia foi liberado à atmosfera na forma de $\mathrm{C}-\mathrm{CO}_{2}$. Os resultados deste estudo mostraram que a velocidade de decomposição da palha de aveia preta não foi alterada pela aplicação de dejetos de suínos, em sistema plantio direto.
\end{abstract}

Termos de indexação: mineralização do C, respiração do solo, adubos orgânicos, seqüestro de C, emissão de $\mathrm{CO}_{2}$.

\footnotetext{
(1) Parte da Tese de Mestrado do segundo autor, apresentada ao Programa de Pós Graduação em Ciência do Solo, Universidade Federal de Santa Maria - UFSM. Pesquisa parcialmente financiada com recursos do Pronex-CNPq/FINEP. Recebido para publicação em novembro de 2003 e aprovado em outubro de 2005.

(2) Professor Adjunto do Departamento de Solos da Universidade Federal de Santa Maria - UFSM. Campus Universitário, CEP 97105900 Santa Maria (RS). Bolsista do CNPq. E-mail: caita@ccr.ufsm.br; sjgiacomini@smail.ufsm.br

(3) Extensionista Rural da Empresa de Pesquisa Agropecuária e Extensão Rural de Santa Catarina - EPAGRI. Av. Presidente Getúlio Vargas 775, CEP 89880-000 Caxambu do Sul (SC). E-mail: ivan_chiapinotto@epagri.ret-sc.br

${ }^{(4)}$ Doutorando do Programa de Pós-Graduação em Ciência do Solo, UFSM. E-mail: andrepaulohubner@yahoo.com.br

(5) Pesquisador Visitante, Centro de Pesquisa Agropecuária de Clima Temperado - CPACT/Embrapa. Rod. BR 392, km 76, Caixa Postal 403, CEP 96001-970 Pelotas (RS). E-mail: marceloagro@yahoo.com.br
} 


\title{
SUMMARY: DECOMPOSITION OF BLACK OAT STRAW AND PIG SLURRY IN A SOIL UNDER NO-TILLAGE
}

\begin{abstract}
The use of pig slurry in no-tillage systems is relatively recent in South Brazil, so it is important to evaluate the decomposition of pig slurry as well as its effects on the cover crop residue decomposition in this system. The objective of this study was to evaluate the pig slurry decomposition and its influence on the decomposition rate of black oat straw in a soil under no-tillage. Two experiments were carried out under field conditions in an experimental area of the Federal University of Santa Maria (UFSM), on a Hapludalf. The $\mathrm{CO}_{2}-\mathrm{C}$ emission was measured right after the application of 0 and $40 \mathrm{~m}^{3} \mathrm{ha}^{-1}$ of pig slurry in static chambers, in the absence or in the presence of oat straw on the soil surface. The $\mathrm{CO}_{2}$ - $\mathrm{C}$ emission was monitored for 62 days in experiment 1 and for 97 days in experiment 2. Pig slurry and oat straw showed a different decomposition pattern. While the pig slurry had an initial phase of fast $\mathrm{CO}_{2}$ - C mineralization followed by a slower phase, $\mathrm{CO}_{2}$-C-liberation by oat straw was more constant. About one third of $C$ added through pig slurry and oat straw was emitted to the atmosphere in the form of $\mathrm{CO}_{2}$-C. Results of this study showed that the decomposition rate of black oat straw was not influenced by pig slurry application in soil under no-tillage system.
\end{abstract}

Index terms: carbon mineralization, soil respiration, organic amendments, carbon sequestration, $\mathrm{CO}_{2}$ emission.

\section{INTRODUÇÃO}

A suinocultura constitui uma das principais atividades econômicas de diversas regiões agrícolas do Sul do Brasil. Pelo fato de tal atividade empregar elevado nível tecnológico, os animais permanecem, na maioria das situações, em regime de total confinamento até o abate, o que resulta em grande acúmulo de dejetos nas unidades de criação.

Diversos trabalhos realizados no Brasil têm evidenciado o elevado potencial fertilizante dos dejetos de suínos (Ernani, 1984; Scherer et al., 1995), e contribuído para impulsionar a construção de estruturas para seu armazenamento, com destaque para as esterqueiras, onde bactérias anaeróbicas atuam na decomposição da fração nitrogenada orgânica das fezes e urina, promovendo o acúmulo gradativo de $\mathrm{N}$ amoniacal. Considerando que a dieta dos animais é rica em proteínas, a proporção de $\mathrm{N}$ amoniacal $\left(\mathrm{N}-\mathrm{NH}_{3}+\mathrm{N}-\mathrm{NH}_{4}{ }^{+}\right)$nos dejetos de suínos manejados na forma líquida é elevada, correspondendo, em média, a $60 \%$ do $\mathrm{N}$ total, como constataram Scherer et al. (1996), ao analisarem 98 amostras de esterqueiras líquidas anaeróbicas da Região Oeste de Santa Catarina.

$\mathrm{Na}$ maioria dos trabalhos publicados até o momento no Brasil, os dejetos de suínos foram aplicados no sistema de preparo convencional, com a sua incorporação ao solo por aração e gradagens (Scherer et al., 1984; Ernani, 1984). Essa recomendação de incorporar os dejetos ao solo logo após a sua aplicação fundamenta-se na necessidade de diminuir as perdas gasosas de $\mathrm{N}$ por volatilização de amônia, preservando o valor fertilizante nitrogenado dos dejetos. Todavia, no sistema plantio direto, cuja área vem aumentando significativamente nos últimos anos na Região Sul, é necessário aplicar os dejetos sem incorporação ao solo. Essa modalidade de aplicação dos dejetos sobre os resíduos culturais de plantas de cobertura ou de plantas invasoras deverá ter implicações diferentes daquelas avaliadas no sistema convencional, especialmente na dinâmica do $\mathrm{C}$ e do $\mathrm{N}$ no solo.

Apesar da estreita relação existente entre a dinâmica do $\mathrm{C}$ e do $\mathrm{N}$ durante a decomposição de materiais orgânicos no solo (Recous et al., 1995; Mary et al., 1996), poucos foram os estudos realizados até o momento para avaliar o efeito dos dejetos de animais sobre a taxa de decomposição dos resíduos culturais de cereais. Nos trabalhos em que esse aspecto foi avaliado, os dejetos e os resíduos sempre foram incorporados ao solo (Saviozzi et al., 1997; Chantigny et al., 2001). Não foi encontrada referência relativa à avaliação da decomposição dos resíduos culturais de gramíneas com o uso de dejetos de suínos em sistema plantio direto. Acredita-se que os dejetos de suínos, ricos em $\mathrm{N}$ mineral, acelerem a decomposição dos resíduos culturais de cereais, caracterizados pelo elevado teor de C facilmente decomponível e pelo baixo teor em $\mathrm{N}$.

Em um experimento realizado em laboratório durante 230 dias a $22{ }^{\circ} \mathrm{C}$ por Saviozzi et al. (1997), a evolução cumulativa de $\mathrm{C}-\mathrm{CO}_{2}$ foi medida em tratamentos com o uso de dejetos de suínos e palha de trigo $(\mathrm{C} / \mathrm{N}=79,6)$ isoladamente e em mistura de ambos. Os autores observaram que os dejetos de suínos estimularam a decomposição da palha de trigo já que a emissão total de C-CO $\mathrm{CO}_{2}$ do tratamento que continha a mistura de dejetos e palha superou 
em $23 \%$ a soma das quantidades de $\mathrm{C}-\mathrm{CO}_{2}$ emitidas pelos tratamentos com o uso isolado de dejetos e de palha.

Resultados similares foram encontrados por Chantigny et al. (2001) em um experimento em campo, em que a palha de cevada (relação $\mathrm{C} / \mathrm{N}=$ 47,3 ) foi incorporada ao solo juntamente com dejetos de suínos (69,6 \% do $\mathrm{N}$ total na forma de amoniacal). Esse sinergismo entre dejetos e palha encontrado nos dois trabalhos foi atribuído ao estímulo proporcionado pelo $\mathrm{N}$ amoniacal aplicado com os dejetos de suínos à população microbiana responsável pela mineralização do $\mathrm{C}$ da palha de trigo e de cevada. E importante salientar que, em ambos os estudos, os dejetos e a palha dos cereais foram incorporados ao solo.

Considerando a carência de informações de pesquisa relativas ao uso de dejetos de suínos em plantio direto, realizou-se o presente trabalho com vistas em avaliar a decomposição de dejetos de suínos e de palha de aveia preta, com ênfase na quantificação do efeito dos dejetos de suínos sobre a velocidade de decomposição de palha de aveia, em condições de campo.

\section{MATERIAL E MÉTODOS}

Este trabalho foi constituído por dois experimentos realizados em campo, em área do Departamento de Solos da Universidade Federal de Santa Maria, na Depressão Central do Estado do Rio Grande do Sul. As coordenadas geográficas do local são $29^{\circ} 45^{\prime}$ Latitude Sul e Longitude $53^{\circ} 42^{\prime}$ W GrW, estando localizada a $95 \mathrm{~m}$ de altitude. A região apresenta uma temperatura média anual de $19,3{ }^{\circ} \mathrm{C}$ e uma precipitação pluviométrica anual de $1.561 \mathrm{~mm}$, com uma umidade relativa média de $82 \%$. Tais características enquadram a região no clima subtropical úmido, tipo Cfa2, conforme Köppen (1936). As temperaturas mínimas alcançam uma média de $9,3{ }^{\circ} \mathrm{C}$, sendo o mês de julho considerado o que apresenta os menores valores. As temperaturas máximas são registradas no mês de janeiro e alcançam uma média diária de $31,8^{\circ} \mathrm{C}$. O solo pertence à Unidade de Mapeamento São Pedro (Brasil, 1973), classificado como Argissolo Vermelho distrófico arênico (Embrapa, 1999).

O experimento 1 foi realizado no período de 23/ $11 / 2000$ a 25/01/2001 (62 dias), utilizando-se o delineamento experimental inteiramente casualizado com três repetições e quatro tratamentos, os quais consistiram da aplicação ou não de dejetos de suínos em solo descoberto e sobre a palha de aveia preta (Avena strigosa Schieb). Cada unidade experimental constituiu-se de uma câmara estática com $30 \mathrm{~cm}$ de diâmetro e $27 \mathrm{~cm}$ de altura, construída a partir de tubos de cloro polivinil (PVC), no interior das quais foram aplicados os seguintes tratamentos: (1) solo descoberto; (2) solo descoberto $+40 \mathrm{~m}^{3} \mathrm{ha}^{-1} \mathrm{de}$ dejetos; (3) solo + palha de aveia; e (4) solo + palha de aveia $+40 \mathrm{~m}^{3} \mathrm{ha}^{-1}$ de dejetos. No experimento 2 , efetuado no período de 24/10/2001 a 28/01/2002 (97 dias), foram avaliados os mesmos quatro tratamentos do experimento 1 , com a diferença de que, além da palha de aveia (parte aérea), também estavam presentes as raízes da cultura. Os valores de temperatura média diária durante a realização dos dois experimentos encontram-se na figura 1 .

Nos dois anos anteriores à instalação do experimento 1, a área foi cultivada no sistema pousio invernal/milho. No momento da colocação das câmaras, todos os resíduos culturais remanescentes na área foram retirados da superfície do solo. Os tratamentos foram instalados no interior das câmaras 10 dias após a sua colocação no campo, de modo a simular o sistema plantio direto, com aplicação dos dejetos sobre a palha da aveia (parte aérea) e solo descoberto (sem palha).

A palha de aveia preta foi obtida com o cultivo dessa espécie em área próxima ao experimento. Após a coleta da parte aérea no estádio de florescimento pleno (07/10/2000), foi feita a secagem ao ar do tecido vegetal em ambiente protegido até massa constante. Antecedendo a instalação do experimento, uma subamostra do material foi seca em estufa a $65{ }^{\circ} \mathrm{C}$, a fim de determinar a quantidade de palha seca ao ar por adicionar em cada câmara para atingir o equivalente a uma produção de palha de aveia de $6.000 \mathrm{~kg} \mathrm{ha}^{-1}$ de matéria seca $\left(65^{\circ} \mathrm{C}\right)$.

No experimento 2, uma parte da área permaneceu em pousio durante o inverno e outra foi cultivada com aveia preta. Na fase de maturação fisiológica da aveia, procedeu-se ao acamamento dessa cultura, utilizando rolo faca, sendo instaladas imediatamente as câmaras sobre os resíduos culturais da aveia (parte aérea + raízes) e no solo descoberto. No dia da rolagem da aveia, procedeu-se à coleta de quatro amostras da parte aérea da cultura, em parcelas de $0,49 \mathrm{~m}^{2}$, submetendo-as à secagem em estufa a $65^{\circ} \mathrm{C}$ até massa constante para a determinação da produção de matéria seca, que foi de $4.396 \mathrm{~kg} \mathrm{ha}^{-1}$. Para avaliar a produção de raízes, foi coletada a camada de 0-30 cm do solo de metade da área onde foi amostrada a parte aérea. Após a separação em jato d'água, as raízes foram secas em estufa a $65{ }^{\circ} \mathrm{C}$ e pesadas. Os dejetos de suínos foram aplicados no interior das câmaras três dias após a sua instalação.

Após a secagem, a palha da aveia dos dois experimentos e as raízes do experimento 2 foram moídas em moinho Willey equipado com peneira 40 mesh. A concentração de $\mathrm{N}$ total $(\mathrm{N})$ do tecido vegetal foi determinada por digestão úmida, conforme Tedesco et al. (1995), e a concentração de C orgânico (C) nos dejetos e no tecido vegetal foi determinada por combustão seca em um analisador LECO modelo CHN 600. 
Os dejetos de suínos eram constituídos pela mistura de fezes e urina dos animais, bem como de outros materiais provenientes do processo criatório, tais como: água desperdiçada dos bebedouros, água de higienização, restos de alimentos, pêlos e poeira. Em decorrência de dificuldades metodológicas em obter uma amostra representativa dos dejetos de suínos "in natura" para determinar as concentrações de $\mathrm{N}$ total e de $\mathrm{N}$ amoniacal, optou-se por separar as frações (líquida e pastosa) desses dejetos por centrifugação, conforme proposição de Scherer et al. (1996). A concentração em N total dessas frações foi determinada por digestão úmida, porém sem o uso de água oxigenada $\left(\mathrm{H}_{2} \mathrm{O}_{2}\right)$, já que a mesma pode provocar a projeção de material orgânico para fora dos tubos durante a fase inicial da digestão (Almeida,
2000). A determinação dos teores de $\mathrm{N}$ amoniacal $\left(\mathrm{N}-\mathrm{NH}_{4}{ }^{+}+\mathrm{N}-\mathrm{NH}_{3}\right)$ foi feita por destilação em destilador de arraste de vapores semi-micro Kjeldahl após a adição de óxido de magnésio $(\mathrm{MgO})$.

Tal método permite determinar separadamente as concentrações de $\mathrm{N}$ total e de $\mathrm{N}$ amoniacal nas frações (pastosa e líquida) dos dejetos de suínos. Por diferença entre essas duas formas de $\mathrm{N}$, é possível calcular a concentração de $\mathrm{N}$ orgânico. Com base nas concentrações dessas três formas de N (total, amoniacal e orgânico) e da proporção entre as frações, pastosa e líquida, pode-se conhecer, para cada forma de $\mathrm{N}$, a sua distribuição quantitativa entre essas frações. Os resultados relativos a esse atributo dos dejetos para os dois experimentos encontram-se no quadro 1.

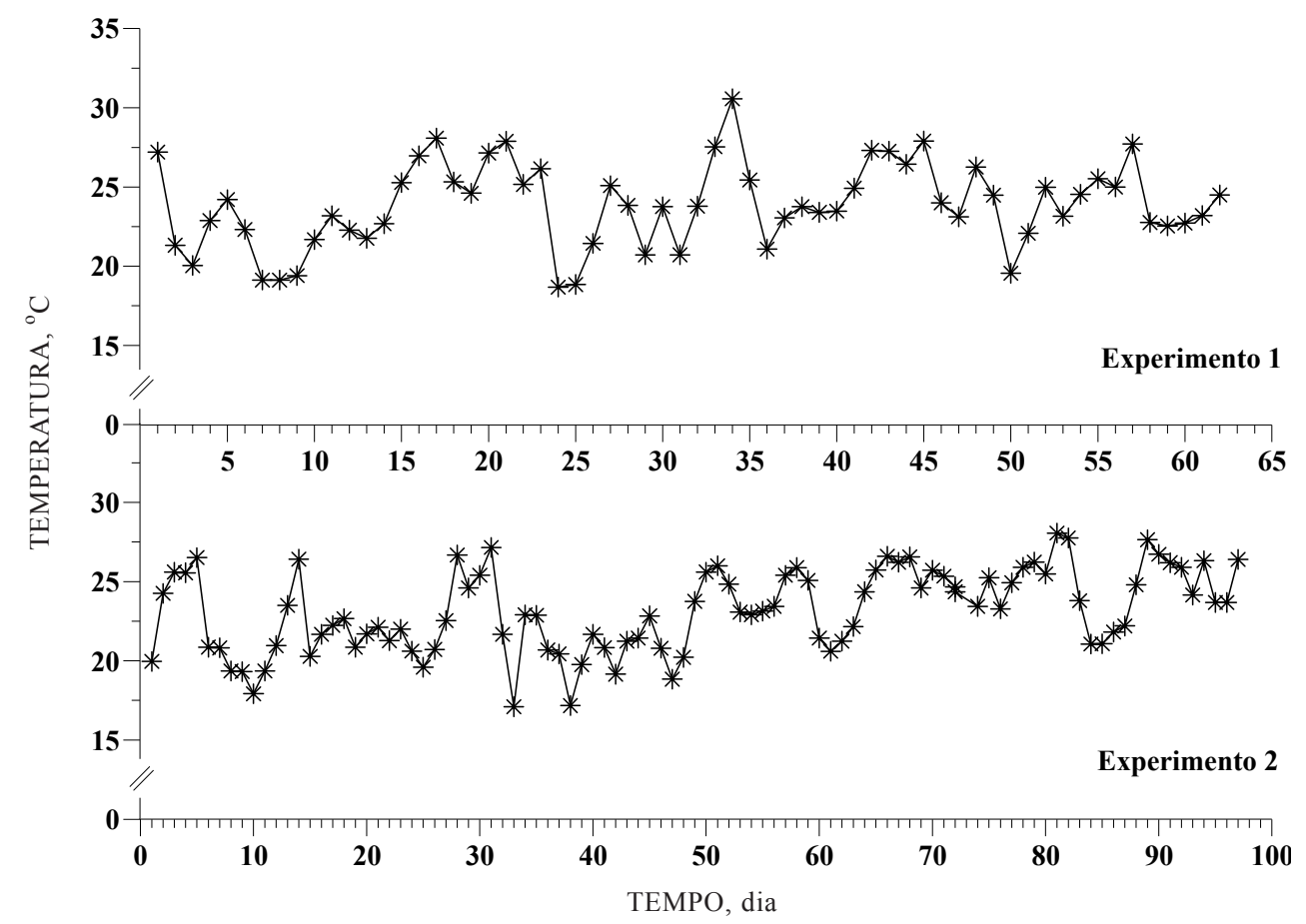

Figura 1. Temperatura média do ar durante os experimentos 1 e 2.

Quadro 1. Quantidades de N total, N amoniacal e N orgânico nas frações (pastosa e líquida) dos dejetos de suínos utilizados nos experimentos 1 e 2

\begin{tabular}{|c|c|c|c|c|c|c|}
\hline \multirow{3}{*}{ Forma de nitrogênio } & \multicolumn{6}{|c|}{ Fração do dejeto } \\
\hline & \multicolumn{3}{|c|}{ Experimento 1} & \multicolumn{3}{|c|}{ Experimento 2} \\
\hline & Pastosa & Líquida & Pastosa + Líquida & Pastosa & Líquida & Pastosa + Líquida \\
\hline $\mathrm{N}$ total ( $\mathrm{kg} \mathrm{m}^{-3}$ de dejetos $)$ & 2,36 & 1,22 & 3,58 & 3,01 & 1,88 & 4,89 \\
\hline $\mathrm{N}$ amoniacal ( $\mathrm{kg} \mathrm{m}^{-3}$ de dejetos) & 0,89 & 1,11 & 2,00 & 1,30 & 1,37 & 2,67 \\
\hline $\mathrm{N}$ amoniacal (\% do $\mathrm{N}$ total) & 37,70 & 91,00 & 55,80 & 43,00 & 72,90 & 54,60 \\
\hline $\mathrm{N}$ orgânico ( $\mathrm{kg} \mathrm{m}^{-3}$ de dejetos) & 1,47 & 0,11 & 1,58 & 1,71 & 0,51 & 2,22 \\
\hline
\end{tabular}


Para determinar a matéria seca dos dejetos, três amostras de aproximadamente $50 \mathrm{~g}$ foram colocadas em copos de becker e submetidas à secagem em estufa a $105^{\circ} \mathrm{C}$, até massa constante. $\mathrm{O}$ valor médio encontrado foi de $4,58 \%$, no experimento 1 , e de $7,34 \%$, no experimento 2 . $\mathrm{O} \mathrm{pH}$ dos dejetos foi medido em potenciômetro, utilizando-se alíquotas de aproximadamente $50 \mathrm{~mL}$ de dejetos "in natura", e o valor médio encontrado foi de 7,2 e 7,8, nos experimentos 1 e 2 , respectivamente.

A composição química e as quantidades adicionadas de matéria seca, $\mathrm{C}$ e $\mathrm{N}$ com os dejetos e com a aveia nos dois experimentos encontram-se nos quadros 2 e 3 .

A decomposição dos dejetos e da palha foi avaliada por meio da medição contínua das quantidades de $\mathrm{C}-\mathrm{CO}_{2}$ liberadas no interior das câmaras estáticas, as quais foram introduzidas a $5 \mathrm{~cm}$ de profundidade no solo e mostraram-se similares àquelas utilizadas por Aita (1996). Cada câmara foi constituída por um cilindro de cloro polivinil (PVC) de $27 \mathrm{~cm}$ de altura por $30 \mathrm{~cm}$ de diâmetro cuja parte superior foi revestida com borracha para facilitar a sua completa vedação pela tampa, impedindo trocas gasosas com a atmosfera externa. A tampa foi constituída de uma chapa de zinco galvanizado, fixada ao cilindro de PVC por meio de quatro parafusos externos, distribuídos simetricamente em sua circunferência. Para evitar variações bruscas na temperatura interna das câmaras, foi colada, sobre a tampa, uma camada de isopor com $1,5 \mathrm{~cm}$ de espessura.

No interior da câmara e a $5 \mathrm{~cm}$ da superfície do solo, foi instalada uma armação em ferro, em forma de "X", para receber o recipiente que continha a solução alcalina $(\mathrm{NaOH} 1 \mathrm{M})$ utilizada para captar o $\mathrm{CO}_{2}$ evoluído. O recipiente com a solução de $\mathrm{NaOH}$ apresentava $4 \mathrm{~cm}$ de altura e $13 \mathrm{~cm}$ de diâmetro e o volume de solução de $\mathrm{NaOH}$ utilizado em cada coleta era de $100 \mathrm{~mL}$.

Em cada coleta, o excesso de $\mathrm{NaOH}$ foi titulado com uma solução ácida ( $\mathrm{HCl} 1 \mathrm{M})$, conforme descrito

Quadro 2. Composição química e quantidades adicionadas de matéria seca, C orgânico, $\mathrm{N}$ total, $\mathrm{N}$ amoniacal e $\mathrm{N}$ orgânico com os dejetos de suínos e com a palha de aveia no experimento 1

\begin{tabular}{|c|c|c|c|c|}
\hline \multirow{2}{*}{ Componente } & \multicolumn{2}{|c|}{ Composição química } & \multicolumn{2}{|c|}{ Quantidade adicionada } \\
\hline & Palha de aveia & Dejeto de suínos & Palha de aveia & Dejeto de suínos \\
\hline & $\mathrm{g} \mathrm{kg}^{-1}$ & $\mathrm{~g} \mathrm{~L}^{-1}$ & - & 1 \\
\hline Matéria seca(1) & $1.000,0$ & 45,70 & 6.000 & 1.830 \\
\hline C orgânico & 441,2 & 16,00 & 2.650 & 640 \\
\hline $\mathrm{N}$ total & 10,3 & 3,57 & 62 & 143 \\
\hline $\mathrm{N}$ amoniacal & - & 2,00 & - & 80 \\
\hline $\mathrm{N}$ orgânico & - & 1,57 & - & 63 \\
\hline Relação C/N (total) & 42,7 & 4,5 & - & - \\
\hline
\end{tabular}

Quadro 3. Composição química e quantidades adicionadas de matéria seca, C orgânico, $\mathrm{N}$ total, $\mathrm{N}$ amoniacal e $\mathrm{N}$ orgânico com os dejetos de suínos e com a palha e raízes de aveia no experimento 2

\begin{tabular}{|c|c|c|c|c|c|c|c|}
\hline \multirow{3}{*}{ Componente } & \multicolumn{3}{|c|}{ Composição química } & \multicolumn{4}{|c|}{ Quantidade adicional } \\
\hline & \multicolumn{2}{|c|}{ Aveia } & \multirow{2}{*}{ Dejeto de suíno } & \multicolumn{3}{|c|}{ Aveia } & \multirow[b]{2}{*}{ Dejeto de suíno } \\
\hline & Palha & Raiz & & Palha & Raiz & Total & \\
\hline & \multicolumn{2}{|c|}{$-\mathrm{g} \mathrm{kg}^{-1}$} & $\mathrm{~g} \mathrm{~L}^{-1}$ & \multicolumn{4}{|c|}{$-\mathrm{kg} \mathrm{ha}^{-1}$} \\
\hline Matéria seca(1) & $1.000,0$ & $1.000,0$ & 73,40 & 4.396 & 1.319 & $5.715,0$ & 2.936 \\
\hline C orgânico & 443,5 & 441,2 & 21,50 & 1.950 & 582 & $2.532,0$ & 860 \\
\hline Nitrogênio total & 10,0 & 9,1 & 4,87 & 44 & 12 & 56,0 & 195 \\
\hline Nitrogênio amoniacal & - & - & 2,97 & - & - & - & 119 \\
\hline Nitrogênio orgânico & - & - & 1,90 & - & - & - & 76 \\
\hline Relação C/N & 44,3 & 48,5 & 4,40 & - & - & 45,2 & - \\
\hline
\end{tabular}

\footnotetext{
(1) Amostra seca em estufa a $65^{\circ} \mathrm{C}$.
} 
por Stotzky (1965). O período de tempo entre cada troca da solução de $\mathrm{NaOH}$ variou conforme a velocidade de decomposição dos materiais orgânicos de modo a evitar a saturação da solução pelo C- $\mathrm{CO}_{2}$ liberado. Assim, as coletas foram diárias nos primeiros 20 dias e a intervalos de 2 a 3 dias após esse período, dependendo das condições climáticas. A medição da evolução de $\mathrm{C}-\mathrm{CO}_{2}$ foi feita alternadamente em dois cilindros que continham o mesmo tratamento. Este procedimento teve por objetivo diminuir a interferência das câmaras sobre as condições ambientais ocorridas durante o experimento.

Para facilitar a distribuição da palha de aveia no interior dos cilindros, na superfície do solo, a palha foi cortada manualmente em pedaços de $15 \mathrm{~cm}$ um dia antes da aplicação dos dejetos. Os dejetos, por sua vez, foram aplicados com o auxílio de um recipiente plástico com capacidade para $2 \mathrm{~L}$, no qual foi acoplada a ponta de um regador, com vistas em proporcionar uma distribuição uniforme dos dejetos. Para evitar a interferência da disponibilidade de água sobre a taxa de decomposição inicial da palha e da matéria orgânica no solo descoberto, adicionouse, na instalação do experimento, nos tratamentos sem adição de dejetos, uma quantidade de água equivalente à dose de $40 \mathrm{~m}^{3} \mathrm{ha}^{-1}$ de dejetos.

Sempre que possível, ao final de cada precipitação pluviométrica, era efetuada a troca da solução receptora $(\mathrm{NaOH})$ e, naquelas câmaras que permaneciam cobertas captando o $\mathrm{CO}_{2}$ evoluído, era adicionada água destilada. Considerando que o movimento lateral d'água das precipitações poderia provocar o umedecimento de parte do solo do interior dos cilindros, optou-se por adicionar, após cada precipitação, apenas 1/3 do seu volume total, medido em pluviômetros instalados junto ao experimento.

A partir das quantidades emitidas de $\mathrm{C}-\mathrm{CO}_{2} \mathrm{em}$ cada tratamento e das quantidades de $\mathrm{C}$ adicionadas ao solo pelos dejetos, palha e raízes de aveia (Quadros 2 e 3), foi calculada a mineralização do C dos materiais orgânicos, utilizando a equação:

$$
\mathrm{C} \text { mineralizado (\%) }=\frac{\mathrm{C}-\mathrm{CO}_{2} \mathrm{~T}-\mathrm{C}-\mathrm{CO}_{2} \mathrm{SD}}{\mathrm{Cad}} \times 100
$$

sendo $\mathrm{C}-\mathrm{CO}_{2} \mathrm{~T}$ e $\mathrm{C}-\mathrm{CO}_{2} \mathrm{SD}$ as quantidades emitidas de $\mathrm{C}-\mathrm{CO}_{2}$ nos tratamentos com materiais orgânicos e no solo descoberto, em $\mathrm{kg} \mathrm{ha}^{-1}$, respectivamente, e Cad a quantidade de $\mathrm{C}$ adicionado ao solo pelos materiais orgânicos, em kg ha-1.

Esse cálculo da mineralização mostra que tanto os dejetos como a palha da aveia não influem na taxa de decomposição da matéria orgânica do solo (efeito "priming"), razão pela qual o valor resultante será chamado de mineralização aparente do C dos materiais orgânicos.

Os dados relativos à mineralização acumulada de $\mathrm{C}$ foram interpretados pela análise da variância, e as médias foram comparadas pelo teste de Tukey a $5 \%$ de probabilidade de erro, considerando os tratamentos isoladamente. Para os dados de fluxo de $\mathrm{C}-\mathrm{CO}_{2}$, foi calculado, em cada data de avaliação, o erro-padrão da média.

\section{RESULTADOS E DISCUSSÃO}

\section{Fluxos de $\mathrm{C}-\mathrm{CO}_{2}$}

Sem a aplicação de dejetos, os fluxos de C- $\mathrm{CO}_{2}$ do tratamento com palha de aveia foram maiores do que no solo descoberto, sendo essas diferenças mais acentuadas no início do experimento (Figura 2). Isso evidencia que a população microbiana do solo e a sua atividade foram rapidamente estimuladas pela adição da palha como fonte de $\mathrm{C}$ e energia, mesmo deixando-a na superfície do solo.

Com as primeiras chuvas, verificou-se que, tanto no experimento 1 (Figura 2a), como no experimento 2 (Figura 2b), ampliou-se a diferença nos fluxos de C-CO $\mathrm{CO}_{2}$ em favor do tratamento com palha, em relação ao solo descoberto. Esse efeito pode ser atribuído à liberação de compostos solúveis em água presentes inicialmente na palha, os quais são constituídos principalmente por açúcares simples e aminoácidos. Esses compostos carbonados são rapidamente metabolizados pelos microrganismos heterotróficos do solo para a produção de energia, necessária à síntese celular (Sylvia et al., 1998).

A intensidade dos fluxos de $\mathrm{C}-\mathrm{CO}_{2}$ do presente trabalho é da mesma ordem de grandeza daquela encontrada em condições de campo por Chantigny et al. (2001), ao avaliarem a decomposição de palha de trigo (4 $\mathrm{Mg} \mathrm{ha}^{-1}$ ), durante 28 dias no verão do Canadá, com temperatura do solo variando de 16 a $30{ }^{\circ} \mathrm{C}$. Embora os autores também tenham encontrado rápida emissão de $\mathrm{C}-\mathrm{CO}_{2}$ na fase inicial de decomposição da palha, dois outros aspectos relativos à cinética de emissão de $\mathrm{C}-\mathrm{CO}_{2}$ diferiram do presente trabalho. $\mathrm{O}$ primeiro deles é que as diferenças dos fluxos de C- $\mathrm{CO}_{2}$ entre os tratamentos com e sem palha foram menores e o segundo é que os fluxos de C-CO $\mathrm{CO}_{2}$ oscilaram menos por ocasião de cada precipitação ocorrida.

Essas diferenças devem estar relacionadas com a distribuição mais uniforme das chuvas no trabalho realizado no Canadá e, principalmente, com o fato de os autores terem incorporado a palha ao solo, enquanto, no presente trabalho, a palha de aveia foi deixada na superfície do solo, simulando o sistema plantio direto. Nesse sistema, ocorre maior variação na umidade (ciclos de umedecimento e secagem) dos resíduos culturais do que no sistema convencional, resultando em maior oscilação na atividade microbiana. Todavia, esse efeito é efêmero, já que, logo após cada chuva, a emissão de $\mathrm{C}-\mathrm{CO}_{2}$ diminui rapidamente, como ilustram os resultados da figura 2 . 


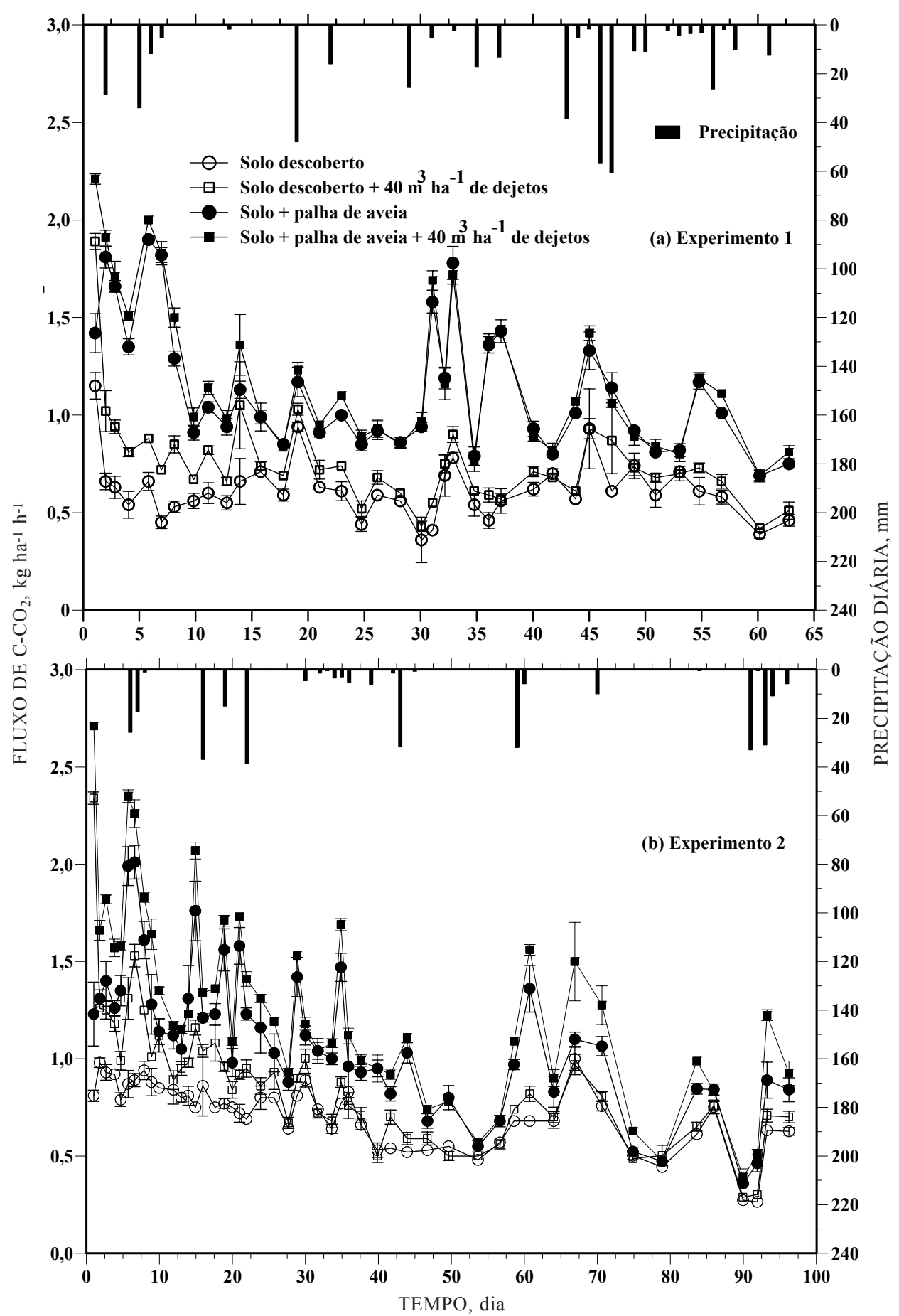

Figura 2. Fluxos de C-CO $\mathrm{CO}_{2}$, com e sem a aplicação de $40 \mathrm{~m}^{3} \mathrm{ha}^{-1}$ de dejetos de suínos em solo descoberto e sobre a palha de aveia preta, e precipitações pluviométricas ocorridas durante os experimentos 1 (a) e 2 (b).

De maneira geral, as variações dos fluxos de C$\mathrm{CO}_{2}$ estão associadas à ocorrência de precipitações pluviométricas, sendo a magnitude dos picos de emissão de C- $\mathrm{CO}_{2}$ maior no tratamento com palha do que no solo descoberto. Isso se deve não apenas à quantidade, mas também à qualidade do $\mathrm{C}$ presente nas duas situações. Na palha, o C faz parte de compostos mais facilmente oxidáveis pelos microrganismos enquanto na matéria orgânica do solo descoberto predominam compostos carbonados humificados e, por isso, mais recalcitrantes.

Comparando os tratamentos com e sem o uso de dejetos em solo descoberto, observou-se que os fluxos de $\mathrm{C}-\mathrm{CO}_{2}$ com aplicação de dejetos foram superiores 
na maioria das avaliações realizadas, sendo possível separar o aumento nos fluxos de C- $\mathrm{CO}_{2}$ provocado pelos dejetos em três fases distintas (Figura 2). Na primeira fase, observada ao final do primeiro dia após a aplicação de $40 \mathrm{~m}^{3} \mathrm{ha}^{-1}$ de dejetos, ocorreu o maior fluxo de C-CO $\mathrm{CO}_{2}$, atingindo $1,89 \mathrm{~kg} \mathrm{ha}^{-1}$ de C$\mathrm{CO}_{2}$, no experimento 1 , e $2,34 \mathrm{~kg} \mathrm{ha}{ }^{-1}$ de C-CO $\mathrm{CO}_{2}$, no experimento 2. Esses valores foram 64 e $189 \%$ superiores aos do solo descoberto e sem aplicação de dejetos.

Esse pico na emissão de $\mathrm{C}-\mathrm{CO}_{2}$ nas primeiras horas após a aplicação de dejetos tem sido observado em outros trabalhos efetuados em campo (Rochette et al., 2000; Chantigny et al., 2001) e não é atribuído à decomposição biológica da fração orgânica dos dejetos, mas, sim, ao C- $\mathrm{CO}_{2}$ liberado a partir do deslocamento do equilíbrio físico-químico dos carbonatos neles presentes. Durante o armazenamento dos dejetos nas esterqueiras, em condições anaeróbicas, ocorre a produção de dióxido de $\mathrm{C}$, por meio da hidrólise da uréia e da decomposição de ácidos orgânicos voláteis (Sommer \& Husted, 1995). Em solução, o $\mathrm{CO}_{2}$ reage com outras espécies, como $\mathrm{NH}_{3}$, formando carbonatos, cujo equilíbrio químico é pH-dependente (Sommer \& Husted, 1995). Os carbonatos acumulados podem ser rapidamente liberados quando dejetos de suínos com $\mathrm{pH}$ alcalino são aplicados em solos ácidos (Sommer \& Sherlock, 1996).

Esse fenômeno foi comprovado por Chantigny et al. (2001), ao aplicarem dejetos de suínos com pH 7,9 em um solo com $\mathrm{pH}_{\mathrm{H} 2 \mathrm{O}} 5,8$. Nesse caso, $5 \%$ do $\mathrm{C}$ adicionado com os dejetos foi liberado como C- $\mathrm{CO}_{2}$, nas primeiras $10 \mathrm{~h}$ de experimento, sendo essa proporção equivalente ao teor inicial de $\mathrm{C}$ inorgânico dos dejetos.

No presente trabalho, o $\mathrm{pH}$ dos dejetos foi de 7,2 e 7,8 nos experimentos 1 e 2 , respectivamente, e o $\mathrm{pH}$ do solo de ambos os experimentos, de 5,6. Com diferenças de uma ou duas unidades entre o $\mathrm{pH}$ do solo e dos dejetos, aumenta consideravelmente a concentração em $\mathrm{CO}_{2}$ dissolvido e gasoso proveniente dos carbonatos presentes nos dejetos (Morvan, 1999). Para Rochette et al. (2000), em valores de $\mathrm{pH}$ inferiores a 7,2, ocorre a dissociação dos carbonatos de amônio e o $\mathrm{CO}_{2}$ é liberado. Portanto, é de se esperar que, em solos ácidos, a intensidade do pico de emissão de $\mathrm{CO}_{2}$ via deslocamento do equilíbrio dos carbonatos logo após a aplicação dos dejetos seja proporcional à concentração de carbonatos e à alcalinidade dos mesmos. Essas duas características estão relacionadas principalmente com o tipo de alimentação fornecida aos animais e com a forma de armazenamento dos dejetos. Tais resultados evidenciam a importância de conhecer a concentração de $\mathrm{C}$ inorgânico nos dejetos de suínos armazenados em condições anaeróbicas em estudos que envolvem a decomposição desse material orgânico no solo.
Na figura 2, observa-se uma segunda fase na emissão de $\mathrm{C}-\mathrm{CO}_{2}$, em que as diferenças nos fluxos de $\mathrm{C}-\mathrm{CO}_{2}$ no solo descoberto, com e sem dejetos, diminuíram gradativamente, em relação à avaliação feita 24 h após a aplicação dos dejetos. Considerando que, nesse período, que vai do final do primeiro dia até aproximadamente trinta dias após a aplicação dos dejetos, não deva haver mais contribuição de $\mathrm{CO}_{2}$ proveniente dos carbonatos, é possível atribuir essas diferenças à decomposição microbiana dos constituintes carbonados dos dejetos. Nessa segunda fase, também observada por Rochette et al. (2000), que a chamaram de fase de ajustamento, alguns compostos orgânicos acumulados durante a fermentação dos dejetos nas esterqueiras são oxidados pela população microbiana heterotrófica do solo. Dentre esses compostos, ricos em energia, predominam ácidos graxos voláteis que contêm de 2 a 6 carbonos, principalmente os ácidos: acético, butírico e propiônico, além de alcoóis e fenóis (Kirchmann \& Lundvall, 1993; Dendooven et al., 1998).

A partir dos 30 dias, as diferenças nos fluxos de C- $\mathrm{CO}_{2}$ no solo descoberto com e sem aplicação de dejetos diminuíram (Figura 2). Nessa terceira fase, os microrganismos atuam na decomposição daqueles substratos orgânicos mais recalcitrantes dos dejetos (Rochette et al., 2000).

De maneira geral, o incremento nos fluxos de C$\mathrm{CO}_{2}$ provocado pela aplicação dos dejetos foi maior quando eles foram aplicados em solo descoberto do que sobre a palha de aveia (Figura 2). Tomando como exemplo os primeiros 15 dias de avaliação do experimento 1 (Figura 2a), a diferença média dos fluxos de C- $\mathrm{CO}_{2}$ entre os tratamentos solo + dejetos $\left(0,89 \mathrm{~kg} \mathrm{ha}^{-1} \mathrm{~h}^{-1}\right)$ e solo $\left(0,61 \mathrm{~kg} \mathrm{ha}^{-1} \mathrm{~h}^{-1}\right)$ mostrou-se $87 \%$ superior à diferença média dos fluxos de C$\mathrm{CO}_{2}$ entre os tratamentos solo + palha + dejetos $\left(1,43 \mathrm{~kg} \mathrm{ha}^{-1} \mathrm{~h}^{-1}\right)$ e solo + palha $\left(1,28 \mathrm{~kg} \mathrm{ha}^{-1} \mathrm{~h}^{-1}\right)$. Esse efeito pode ser atribuído à barreira física criada pela palha da aveia, diminuindo o contato entre os dejetos e o solo. É provável que parte da fração orgânica dos dejetos tenha permanecido sobre a palha da aveia, dificultando o acesso ao $\mathrm{C}$ dos mesmos por parte dos microrganismos do solo. Este resultado evidencia que, provavelmente, para doses equivalentes de dejetos de suínos, a sua contribuição para o C orgânico do solo será maior quando eles forem aplicados sobre os resíduos culturais da aveia do que em solo descoberto.

\section{Mineralização acumulada de C}

A partir do terceiro dia no experimento 1 (Figura 3a) e do sétimo dia no experimento 2 (Figura $3 \mathrm{~b}$ ), a diferença na quantidade liberada de C- $\mathrm{CO}_{2}$ em favor do tratamento com palha de aveia, em relação ao solo descoberto, aumenta gradativamente com o passar do tempo. Observa- 
se também que há dois grupos de tratamentos quanto à liberação cumulativa de $\mathrm{C}-\mathrm{CO}_{2}$ : um grupo é representado pela palha de aveia, com e sem o uso de dejetos, o qual diferiu significativamente do outro grupo de tratamentos, incluindo o solo descoberto, com e sem dejetos.

A mineralização aparente acumulada de $\mathrm{C}$, expressa como uma percentagem do $\mathrm{C}$ adicionado nos diferentes tratamentos (Figura 4), indica uma cinética distinta na decomposição da fração carbonada dos dejetos e da palha da aveia, em conformidade com os resultados de Saviozzi et al. (1997). Nos dejetos de suínos, é evidente a natureza curvilínea do $\mathrm{C}$ mineralizado com o tempo, especialmente no experimento 2 (Figura 4b), apresentando uma taxa inicial mais elevada de mineralização do $\mathrm{C}$ seguida por uma tendência à estabilização dos valores durante o restante do período. Já na palha de aveia, essa natureza curvilínea é menos evidente e não há

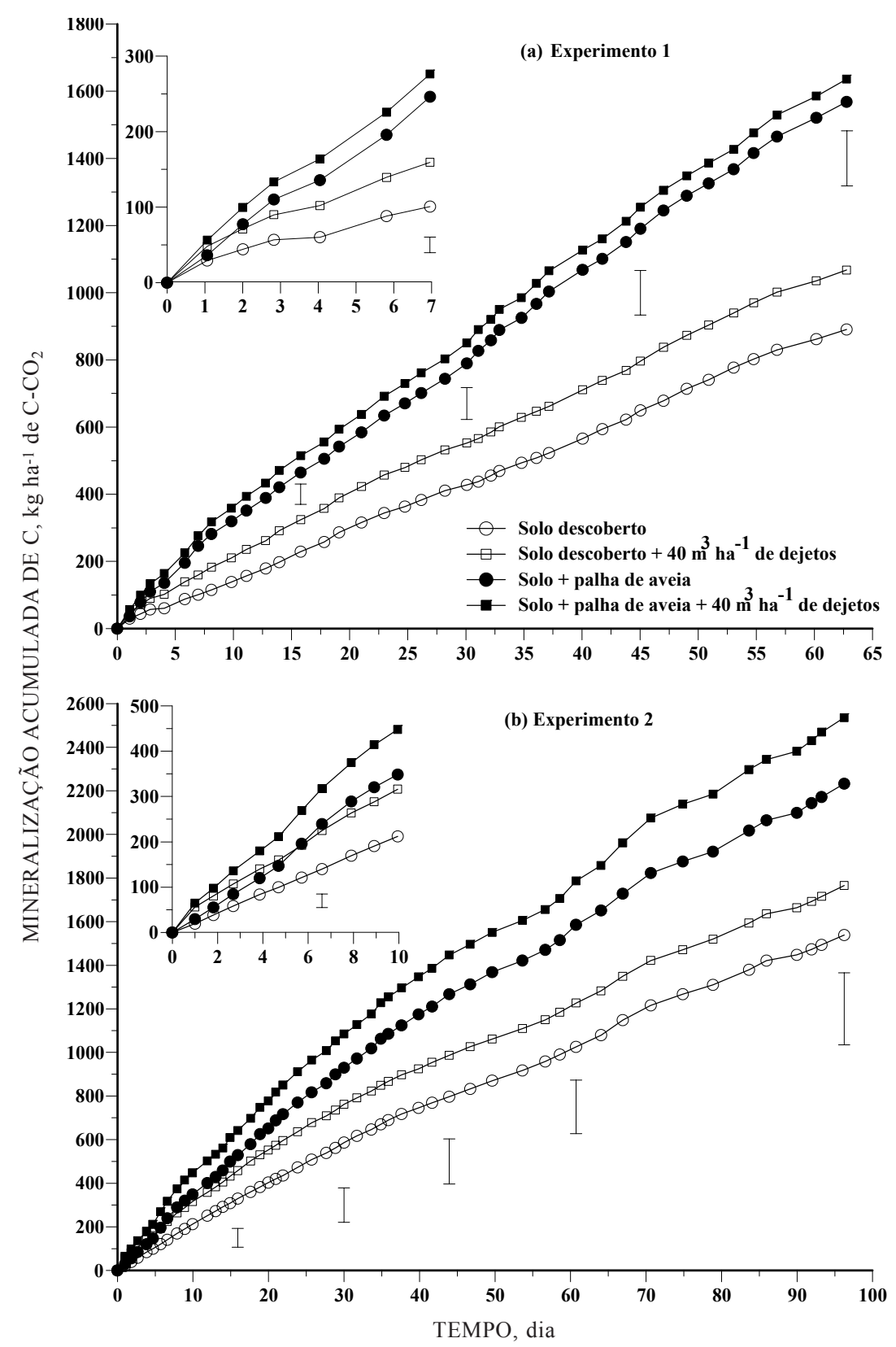

Figura 3. Mineralização acumulada de C $\left(\mathrm{kg} \mathrm{ha}^{-1} \mathrm{de} \mathrm{C}-\mathrm{CO}_{2}\right)$, com e sem a aplicação de $40 \mathrm{~m}^{3} \mathrm{ha}^{-1} \mathrm{de} \mathrm{dejetos}$ de suínos em solo descoberto e sobre a palha de aveia nos experimentos 1 (a) e 2 (b). A figura menor, no detalhe, refere-se a uma ampliação do intervalo de 0 a 7 dias no experimento 1 e de 0 a 10 dias no experimento 2 . As barras verticais indicam a diferença mínima significativa (Tukey a $5 \%$ ) em datas de avaliação, escolhidas aleatoriamente. 
sinais de estabilização na mineralização do $\mathrm{C}$ até o final do período avaliado.

Essa diferença na cinética de decomposição dos dois materiais orgânicos pode ser atribuída às diferenças na sua composição bioquímica inicial. Saviozzi et al. (1997) verificaram que a proporção entre as frações mais lábeis e mais recalcitrantes diferiu entre os dejetos de suínos e a palha de trigo, com os dejetos apresentando maior concentração em fração solúvel e menor em material fibroso. Tais diferenças na composição bioquímica podem alterar a estrutura da comunidade da biomassa microbiana e afetar a sua eficiência no uso do C, resultando em diferenças na mineralização do $\mathrm{C}$ de diferentes fontes orgânicas.

Observa-se que aproximadamente $25 \%$ do $\mathrm{C}$ da

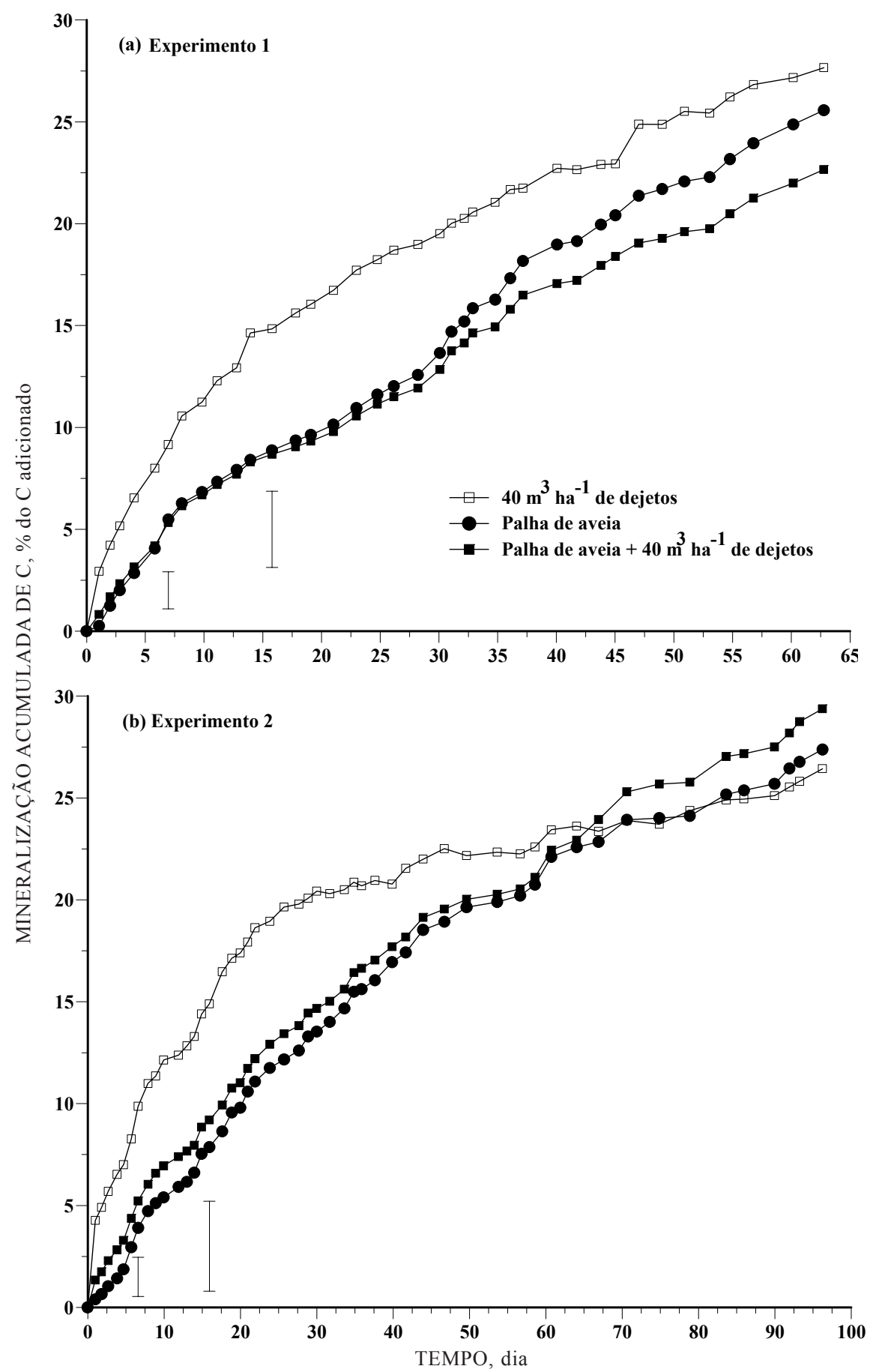

Figura 4. Mineralização acumulada do C (\% do C adicionado) proveniente dos dejetos, da palha de aveia e da mistura de dejetos e palha, nos experimentos 1 (a) e 2 (b). As barras verticais indicam a diferença mínima significativa (Tukey a 5 \%) em datas de avaliação, escolhidas aleatoriamente. 
palha foram mineralizados em 62 dias, no experimento 1, e $27 \%$ no experimento 2 (Figura 4). Já nos dejetos aplicados em solo descoberto, a mineralização aparente do $\mathrm{C}$ foi de aproximadamente $28 \%$, no experimento 1 , e de $26 \%$ no experimento 2 . É importante destacar que esse índice de mineralização encontrado para os dejetos pode estar superestimado, em decorrência da emissão inicial não-biológica de $\mathrm{CO}_{2}$, pela dissociação dos carbonatos dos dejetos.

Esse problema da interferência do C inorgânico na quantificação da mineralização do $\mathrm{C}$ dos dejetos de suínos foi abordado por Chantigny et al. (2001), que desconsideraram o $\mathrm{C}-\mathrm{CO}_{2}$ emitido em todos os tratamentos nas primeiras $10 \mathrm{~h}$ para o cálculo da mineralização do C dos dejetos, e por Morvan (1999), que considerou ter todo o C inorgânico dos dejetos volatilizado nas primeiras $24 \mathrm{~h}$.

$\mathrm{O}$ teor de $\mathrm{C}$ inorgânico dos dejetos não foi determinado no presente trabalho. Considerando que, nas primeiras 24 horas do experimento 1, a diferença de $18,8 \mathrm{~kg} \mathrm{ha}^{-1}$ de $\mathrm{C}-\mathrm{CO}_{2}$ entre a quantidade de $\mathrm{C}-\mathrm{CO}_{2}$ emitida na dose de $40 \mathrm{~m}^{3} \mathrm{ha}^{-1}$ (48,2 $\mathrm{kg} \mathrm{ha}^{-1}$ de C- $\mathrm{CO}_{2}$ ) e aquela do solo descoberto $\left(29,4 \mathrm{~kg} \mathrm{ha}^{-1}\right.$ de $\left.\mathrm{C}-\mathrm{CO}_{2}\right)$ corresponda ao $\mathrm{C}-\mathrm{CO}_{2}$ volatilizado dos carbonatos, a mineralização do $\mathrm{C}$ dos dejetos diminuiria de 28 para $25 \%$. Fazendo esse mesmo cálculo para o experimento 2 , a mineralização aparente do $\mathrm{C}$ dos dejetos diminuiria de 26 para $22 \%$. Convém destacar que, na maioria dos trabalhos (Dendooven et al., 1998; Rochette et al., 2004), o cálculo da mineralização do C dos dejetos é feito sem levar em conta essa problemática da presença de C inorgânico e da sua rápida emissão para a atmosfera após a aplicação dos dejetos no solo.

Essa percentagem de mineralização aparente dos dejetos, encontrada nos dois experimentos, pode ser considerada baixa, relativamente a outros estudos. Em um trabalho realizado no campo durante 28 dias por Chantigny et al. (2001), tempo em que a temperatura do solo variava de 16 a $30^{\circ} \mathrm{C}$ e com os dejetos incorporados ao solo, os autores verificaram que, ao final do experimento, $34 \%$ do $\mathrm{C}$ dos dejetos foram perdidos como $\mathrm{CO}_{2}$. Também em condições de campo e com a incorporação dos dejetos de suínos ao solo, Rochette et al. (2004) encontraram $63 \%$ de mineralização do C dos dejetos ao final de 37 dias. Em condições de laboratório, Saviozzi et al. (1997) incorporaram uniformemente dejetos de suínos ao solo e avaliaram a sua decomposição durante 230 dias a uma temperatura de $22^{\circ} \mathrm{C}$. Analisando a liberação cumulativa de $\mathrm{C}-\mathrm{CO}_{2}$ proveniente dos dejetos encontrada por esses autores, é possível calcular uma mineralização de aproximadamente $30 \%$ do $\mathrm{C}$ adicionado para os primeiros 30 dias de incubação.

No presente trabalho, o cálculo da mineralização aparente do $\mathrm{C}$ dos dejetos com base na avaliação feita aos 30 dias resultou numa mineralização de
19 e $20 \%$, nos experimentos 1 e 2 , respectivamente (Figura 4).

Neste estudo, a menor mineralização do C dos dejetos deve estar relacionada com duas causas principais: a primeira refere-se a possíveis diferenças na composição bioquímica dos dejetos nos diferentes trabalhos e a segunda envolve o sistema de preparo do solo utilizado quando da aplicação dos dejetos. Com a incorporação dos dejetos ao solo, seja no campo, seja em condições controladas, é facilitado o acesso dos microrganismos ao $\mathrm{C}$ adicionado. Já em sistema plantio direto, esse contato entre os microrganismos e a fonte de $\mathrm{C}$ e energia (dejetos) pode ser limitado à interface solo/dejetos. Além disso, com a permanência dos resíduos orgânicos na superfície do solo, a atividade dos organismos decompositores mostra-se muito mais susceptível às condições climáticas adversas do que no sistema convencional, quando os resíduos são incorporados ao solo.

Quanto à palha de aveia, a mineralização aparente de $13 \%$ do $\mathrm{C}$, encontrada aos 30 dias (Figura 4), é próxima daquela relatada por Chantigny et al. (2001), de $12 \%$ para a palha de cevada $(\mathrm{C} / \mathrm{N}=47,2)$ em 28 dias. Já Saviozzi et al. (1997) encontraram aproximadamente $18 \%$ de mineralização para o $\mathrm{C}$ de palha de trigo $(\mathrm{C} / \mathrm{N}=79,6)$ em 30 dias. Esses resultados evidenciam a diferença na qualidade dos componentes carbonados dos dejetos de suínos e os resíduos culturais de gramíneas.

Um aspecto interessante a destacar na figura 4 é que, tanto na palha de aveia como nos dejetos, utilizados isoladamente ou misturados, apenas 25 a $30 \%$ do $\mathrm{C}$ adicionado foram liberados como C- $\mathrm{CO}_{2}$ durante a decomposição desses materiais orgânicos no solo, evidenciando o potencial de retenção do $\mathrm{C}$ dos mesmos no solo, nas condições do presente estudo.

\section{Efeito dos dejetos sobre a decomposição dos resíduos culturais da aveia}

A partir dos resultados da figura 3, é possível avaliar o efeito dos dejetos sobre a decomposição dos resíduos culturais da aveia. No experimento 1 , a quantidade de $\mathrm{C}-\mathrm{CO}_{2}$ proveniente do tratamento com a aplicação de $40 \mathrm{~m}^{3} \mathrm{ha}^{-1}$ de dejetos sobre a palha da aveia foi de $745 \mathrm{~kg} \mathrm{ha}^{-1}$ de $\mathrm{C}-\mathrm{CO}_{2}$ (descontando o C- $\mathrm{CO}_{2}$ do solo descoberto) aos 62 dias, sendo $13 \%$ inferior à soma do $\mathrm{C}-\mathrm{CO}_{2}$ proveniente dos dejetos $\left(177 \mathrm{~kg} \mathrm{ha}^{-1}\right.$ de $\left.\mathrm{C}-\mathrm{CO}_{2}\right)$ e da palha da aveia (678 $\mathrm{kg} \mathrm{ha}^{-1}$ de $\mathrm{C}-\mathrm{CO}_{2}$ ), quando utilizados isoladamente.

Considerando a avaliação feita aos 61 dias no experimento 2 , o $\mathrm{C}-\mathrm{CO}_{2}$ liberado proveniente do tratamento com a mistura de dejetos e aveia (parte aérea +raízes) de $757 \mathrm{~kg} \mathrm{ha}^{-1}$ de C- $\mathrm{CO}_{2}$ é equivalente à soma do $\mathrm{C}-\mathrm{CO}_{2}$ proveniente dos tratamentos somente com dejetos (202 $\mathrm{kg} \mathrm{ha}^{-1}$ de $\left.\mathrm{C}-\mathrm{CO}_{2}\right)$ e aveia 
(557 kg ha ${ }^{-1}$ de $\mathrm{C}-\mathrm{CO}_{2}$ ). Tais resultados evidenciam a inexistência de uma interação positiva quando dejetos de suínos são aplicados diretamente sobre os resíduos de aveia, não se confirmando a hipótese inicial de que a adição de quantidades elevadas de $\mathrm{N}$ mineral com os dejetos (80 kg ha-1 de $\mathrm{N}$ amoniacal no experimento 1 e $119 \mathrm{~kg} \mathrm{ha}^{-1}$ de $\mathrm{N}$ amoniacal no experimento 2) estimularia a decomposição de resíduos culturais ricos em $\mathrm{C}$ oxidável.

Esses resultados diferem daqueles obtidos em condições de campo por Chantigny et al. (2001), onde os dejetos aumentaram a decomposição da palha de cevada em $26 \%$, e, em condições de laboratório, por Saviozzi et al. (1997), em que a decomposição da palha de trigo aumentou em $23 \%$ quando na presença dos dejetos de suínos. Acredita-se que as condições edafoclimáticas e a forma como os dejetos e a palha foram aplicados ao solo no presente trabalho e naqueles conduzidos por Chantigny et al. (2001) e Saviozzi et al. (1997) justifiquem a diferença entre os resultados encontrados, com relação ao efeito dos dejetos sobre a velocidade de decomposição da palha. A incorporação uniforme dos materiais orgânicos ao solo, conforme efetuado por esses autores, deve otimizar a relação entre as dinâmicas do $\mathrm{N}$ e do $\mathrm{C}$ durante a decomposição, fazendo com que o aumento na disponibilidade de $\mathrm{N}$, condicionada pelos dejetos, estimule a população microbiana do solo acelerando a mineralização do C da palha. A composição bioquímica dos resíduos culturais e dos dejetos utilizados em cada trabalho também pode contribuir para as diferenças observadas.

Em plantio direto, é provável que a permanência dos resíduos culturais na superfície do solo dificulte o acesso da população microbiana do solo ao $\mathrm{C}$ dos resíduos culturais e ao $\mathrm{N}$ mineral dos dejetos, impedindo que apareça a interação positiva entre dejetos e resíduos culturais, normalmente observada em preparo convencional, com a incorporação dos materiais ao solo. Com a ocorrência de chuvas logo após a distribuição dos dejetos, conforme verificado nos experimentos 1 e 2 (Figura 2), é provável que essa interação seja ainda mais desfavorecida em plantio direto já que o $\mathrm{N}$ amoniacal presente nos dejetos poderá sair por lixiviação e, ou, escoamento superficial da zona de decomposição ativa, onde se encontra a fonte de $\mathrm{C}$ e onde o $\mathrm{N}$ será necessário à assimilação dos microrganismos para a síntese celular.

Um aspecto que poderia ser especulado é que se houve efeito dos dejetos no aumento da decomposição da palha, quando ambos os materiais orgânicos foram aplicados conjuntamente, ele poderia ser anulado pelo efeito de barreira física da palha, diminuindo a decomposição da fração orgânica dos dejetos que ficaram sobre a palha. Para separar esses efeitos e quantificar precisamente o efeito dos dejetos sobre a decomposição da palha (mineralização real), seria necessário utilizar palha marcada com o isótopo radioativo ${ }^{14} \mathrm{C}$ ou o isótopo estável ${ }^{13} \mathrm{C}$, medindo-se a emissão de ${ }^{14} \mathrm{C}-\mathrm{CO}_{2}$ ou ${ }^{13} \mathrm{C}$ $\mathrm{CO}_{2}$, conforme efetuado por Aita (1996). De qualquer maneira, embora não se possam identificar as causas exatas da ausência de interação positiva entre dejetos e palha, com base nos resultados desses dois experimentos, verifica-se que a emissão de $\mathrm{C}-\mathrm{CO}_{2}$ da mistura de dejetos e palha não foi maior do que aquela resultante da soma do $\mathrm{C}-\mathrm{CO}_{2}$ proveniente dos dejetos e da palha isoladamente.

A ausência de efeito sinergístico entre dejetos de suínos e a palha de aveia, em que o $\mathrm{N}$ mineral dos dejetos não estimulou a mineralização do $\mathrm{C}$ dos resíduos, é positiva tanto do ponto de vista ambiental como da qualidade do solo, já que diminui a emissão de $\mathrm{C}-\mathrm{CO}_{2}$ e aumenta a retenção de $\mathrm{C}$ no solo.

\section{CONCLUSÕES}

1. A velocidade de decomposição da palha de aveia preta não foi alterada pela aplicação de dejetos de suínos em sistema plantio direto.

2. Nos dejetos de suínos, houve uma fase inicial de rápida liberação de $\mathrm{C}-\mathrm{CO}_{2}$, seguida de outra mais lenta, enquanto, na palha de aveia, a liberação de $\mathrm{C}-\mathrm{CO}_{2}$ foi praticamente constante, o que evidencia que a cinética de decomposição destes dois materiais orgânicos no solo foi diferente.

3. A mineralização de aproximadamente um terço do $\mathrm{C}$ dos dejetos e da palha de aveia em três meses mostrou o elevado potencial de retenção do $\mathrm{C}$ desses materiais orgânicos no solo, nas condições edafoclimáticas presentes.

\section{LITERATURA CITADA}

AITA, C. Couplage des cycles du carbone et de l'azote dans les sols cultivés: Étude, au champ, des processus de décomposition après apport de matière organique fraîche. Paris, Université Paris 6, Sciences de la Terre, 1996. 209p. (Tese de Doutorado)

ALMEIDA, A.C.R. Uso associado de esterco líquido de suínos e plantas de cobertura de solo na cultura do milho. Santa Maria, Universidade Federal de Santa Maria, 2000. 144p. (Tese de Mestrado)

BRASIL. Ministério da Agricultura. Departamento Nacional de Pesquisa Agropecuária. Divisão de Pesquisa Pedológica. Levantamento de reconhecimento dos solos do Estado do Rio Grande do Sul. Recife, 1973. 431p. (Boletim Técnico, 30)

CHANTIGNY, M.H.; ROCHETTE, P. \& ANGERS, D.A. Shortterm $\mathrm{C}$ and $\mathrm{N}$ dynamics in a soil amended with pig slurry and barley straw: a field experiment. Can. J. Soil Sci., 81:131-137, 2001. 
DENDOOVEN, L.; BONHOMME, E.; MERCKX, R. \& VLASSAK, K. Injection of pig slurry and its effects on dynamics of nitrogen and carbon in a loamy soil under laboratory conditions. Biol. Fertil. Soils, 27:5-8, 1998.

ERNANI, P.R. Necessidade da adição de N para o milho em solo fertilizado com esterco de suínos, cama de aves e adubos minerais. R. Bras. Ci. Solo, 8:313-317, 1984.

EMPRESA BRASILEIRA DE PESQUISA AGROPECUÁRIA - EMBRAPA. Centro Nacional de Pesquisa de Solos. Sistema Brasileiro de Classificação de Solos. Brasília, 1999. $412 \mathrm{p}$.

KIRCHMANN, H. \& LUDVALL, A. Relationships between N immobilization and volatile fatty acids in soil after application of pig and cattle slurry. Biol. Fertil. Soils, 15:161 164, 1993.

KÖPPEN, W. Grundriss der Klimakunde. Berlin, Guyter, 1936. $388 \mathrm{p}$.

MARY, B.; RECOUS, S.; DARWIS, D. \& ROBIN, D. Interactions between decomposition of plant residues and nitrogen cycling in soil. Plant Soil, 181:71-82, 1996.

MORVAN, T. Quantification et modélisation des flux d'azote résultant de l'épandage de lisier. Paris, Université Paris 6 , Sciences de la Terre, 1999. 157p. (Tese de Doutorado)

RECOUS, S.; ROBIN, D.; DARWIS, D. \& MARY, B. Soil inorganic $\mathrm{N}$ availability: effect on maize residue decomposition. Soil Biol. Biochem., 27:1529-1538, 1995.

ROCHETTE, P.; ANGERS, D. A. \& CÔTÉ, D. Soil carbon and nitrogen dynamics following application of pig slurry for the 19th consecutive year: I: Carbon dioxide fluxes and microbial biomass carbon. Soil Sci. Soc. Am. J., 64:13891395,2000

ROCHETTE, P.; ANGERS, D.A.; CHANTIGNY, M.H.; BERTRAND, N. \& CÔTÉ, D. Carbon dioxide and nitrous oxide emissions following fall and spring applications of pig slurry to an agricultural soil. Soil Sci. Soc. Am. J., 68:14101420,2004
SAVIOZZI, A.; LEVI-MINZI, R.; RIFFALDI, R. \& VANNI, G. Role of chemical constituents of wheat straw and pig slurry on their decomposition in soil. Biol. Fertil. Soils, 25:401-406, 1997.

SCHERER, E.E.; CASTILHOS, E.G.; JUCKSCH, I. \& NADAL, R. Efeito da adubação com esterco de suínos, $\mathrm{N}$ e fósforo em milho. Florianópolis, Empresa Catarinense de Pesquisa Agropecuária, 1984. 26p. (Boletim Técnico, 24)

SCHERER, E.E.; BALDISSERA, I.T. \& DIAS, L.F.X. Potencial fertilizante do esterco líquido de suínos da região Oeste Catarinense. Agropec. Catarinense, 8:35-39, 1995.

SCHERER, E.E.; AITA, C. \& BALDISSERA, I.T. Avaliação da qualidade do esterco líquido de suínos da região Oeste Catarinense para fins de utilização como fertilizante. Florianópolis, Empresa Catarinense de Pesquisa Agropecuária, 1996. 46p. (Boletim Técnico, 79)

SOMMER, S.G. \& HUSTED, S. The chemical buffer system in raw and digested animal slurry. J. Agric. Sci., 124:45-53, 1995.

SOMMER, S.G. \& SHERLOCK, R.R. pH and buffer component dynamics in the surface layers of animal slurries. J. Agric. Sci., 127:109-116, 1996.

STOTZKY, G. Microbial respiration. In: BLACK, C.A.; EVANS, D.D. \& WHITE, J.L., eds. Methods of soil analysis. Part 2. Madison, American Society of Agronomy, 1965 p.1550-1572.

SYLVIA, D.M.; FUHRMANN, J.J.; HARTEL, P.G. \& ZUBERER, D.A. Principles and applications of soil microbiology. New Jersey, Prentice Hall, 1998. 550p.

TEDESCO, M.J.; GIANELLO, C.; BISSANI, C.A.; BOHEN, H. \& VOLKWEISS, S.J. Análises de solo, plantas e outros materiais. Porto Alegre, Universidade Federal do Rio Grande do Sul, 1995. 174p. 